\title{
Effects of liquid metabolite combinations produced by Lactobacillus plantarum on growth performance, faeces characteristics, intestinal morphology and diarrhoea incidence in postweaning piglets
}

\author{
T. V. Thu • Teck Chwen Loh • H. L. Foo • H. Yaakub • \\ M. H. Bejo \\ Accepted: 1 July 2010 / Published online: 15 July 2010 \\ (C) The Author(s) 2010. This article is published with open access at Springerlink.com
}

\begin{abstract}
A study was carried out to investigate the effects of feeding liquid metabolite combinations produced by Lactobacillus plantarum strains on growth performance, diarrhoea incidence, faecal $\mathrm{pH}$, microfloral counts, shortchain fatty acids (SCFA) and intestinal villus height and crypt depth of postweaning piglets. A total of 120 piglets (26 days old) were randomly assigned evenly into five treatment groups treated with same basal diet: (1) -ve control (free antibiotic); (2)+ve control $(0.03 \%$ of chlortetracycline); (3) Com 1 (0.3\% metabolite of TL1, RG11 and RI11 strains); (4) Com 2 (0.3\% metabolite of TL1, RG14 and RS5 strains); (5) Com 3 (0.3\% metabolite of RG11, RG14 and RI11 strains). After 5 weeks, the average daily feed intake was not significantly different $(P>0.05)$ among the treatments and feed conversion ratio was the highest $(P<0.05)$ in the - ve control group. In addition, diarrhoea incidence was reduced when piglets were fed with metabolite combinations. Faecal lactic acid bacteria (LAB) counts were significantly higher $(P<0.05)$ in metabolite treatment groups than in the groups without metabolites. However, the treatment of Com 2 metabolite resulted lower
\end{abstract}

T. V. Thu $\cdot$ T. C. Loh $(\bowtie) \cdot$ H. Yaakub

Department of Animal Science, Faculty of Agriculture,

Universiti Putra Malaysia,

43400 UPM Serdang, Selangor, Malaysia

e-mail: tcloh@putra.upm.edu.my

H. L. Foo

Department of Bioprocess Technology, Faculty of Biotechnology and Biomolecular Science, Universiti Putra Malaysia,

43400 UPM Serdang, Selangor, Malaysia

M. H. Bejo

Department of Veterinary Pathology,

Faculty of Veterinary Medicine, Universiti Putra Malaysia,

43400 UPM Serdang, Selangor, Malaysia
$(P<0.05)$ faecal $\mathrm{pH}$ and Enterobacteriaceae (ENT) than the -ve control group. In contrast, total faecal SCFA of Com 2 were significantly higher $(P<0.05)$ than the $-v e$ control group. The villus height of duodenum was higher $(P<0.05)$ in the + ve control and Com 2 groups as compared to -ve control group. The results obtained in this study showed that feeding metabolite combinations could improve growth performance, and increase the population of gut LAB and faecal SCFA of postweaning piglets.

Keywords Metabolite combination · Faecal microflora . Short-chain fatty acids · Diarrhoea incidence $\cdot$ Postweaning piglets

\section{Introduction}

Postweaning piglets suffer several stress factors including nutritional, environmental and social status. Gut imbalance frequently occurred in postweaning piglets due the increased population of Enterobacteriaceae (ENT) and decreased population of lactic acid bacteria (LAB) (Loh et al. 2002; Taras et al. 2006). Therefore, diarrhoea incidence is usually encountered in piglets immediately after weaning which is associated with a reduction in voluntary feed intake, poor growth rate, intestinal villus atrophy and overall gut malfunction.

The application of sub-therapeutic antibiotics has been used in piglet diets to promote the growth performance and reduce diarrhoea incidence (Jones et al. 1984). However, this procedure has public health consequences due to high risk of resistance of pathogenic bacteria in animal products. It is therefore necessary to find the ways to replace antibiotics in piglet feeding strategies. The use of pre- and 
probiotics (Jensen 1998), fermented feed (Van Winsen et al. 2001), organic acids (Roth and Kirchgessner 1998) and enzymes (Makkink et al. 1994) in piglet diets have been suggested.

Recently, metabolites of LAB has been shown to have probiotic effects, which contain antibacterial substances such as lactic, acetic, propionic, butyric acids, ethanol, hydrogen peroxide and bacteriocins (Foo et al. 2005; Thanh et al. 2009). These substances were able to reduce the $\mathrm{pH}$ and the opportunistic pathogens. Loh et al. (2009) reported that feeding of spray-dried metabolites produced by Lactobacillus plantarum could reduce faecal $\mathrm{pH}$ and ENT population in rats. Moreover, Thanh et al. (2009) demonstrated the feeding of probiotic metabolites improved the growth performance, reduced faecal $\mathrm{pH}$ and increased faecal LAB population in broiler chickens. However, the information of probiotic metabolites effects on piglet growth performance, gut microflora and faecal short-chain fatty acids (SCFA) is still limited. Thus, the objective of this study was to evaluate the effects of liquid metabolite combinations produced by $L$. plantarum on growth performance, faeces characteristics, intestinal villi height and diarrhoea incidence in postweaning piglets.

\section{Materials and methods}

\section{Preparation of LAB metabolites}

The metabolites were produced from five strains of L. plantarum, namely, TL1, RG11 RG14, RS5 and RI11. The L. plantarum strains were isolated from Malaysian food (Foo et al. 2003) and kept at $-20^{\circ} \mathrm{C}$ in Man Rogosa Sharpe broth (MRS; Merck, Darmstadt, Germany) containing $20 \%(\mathrm{v} / \mathrm{v})$ glycerol. The stock culture was revived twice in MRS broth and incubated anaerobically at $30^{\circ} \mathrm{C}$ for $48 \mathrm{~h}$. The liquid metabolites were prepared according to the method as described by Foo et al. (2003). Metabolites were collected by separating the producer cell by centrifugation at $12,000 \mathrm{rpm}$ for $15 \mathrm{~min}$ at $4^{\circ} \mathrm{C}$ and stored at $4^{\circ} \mathrm{C}$ until used. The combinations were mixed by equal volume from each strain before being fed to piglets in their diets.

Animals and diets

This experiment was carried out at the Commercial Research Unit in a pig farm, Tanjung Sepat, Selangor, Malaysia. The protocol used in this experiment complied with the guidelines by the ethical committee of University Putra Malaysia. A total of 120 postweaning crossbred male piglets (Large White $\times$ Landrace $\times$ Duroc) of 20 litters from third to fourth parity of sows, at 26 days of age with an average initial body weight (BW) of $6.32 \pm 0.14 \mathrm{~kg}$ were used in this study. The piglets were kept in raised slatted floor pens $(1.2 \times 1.6 \mathrm{~m})$ at temperature ranging from $26^{\circ} \mathrm{C}$ to $32^{\circ} \mathrm{C}$ and the humidity was $86 \pm 4 \%$. Heater was provided from 20:00 to 08:00 daily to keep the piglets warm. Each pen consisted of four piglets and six replications were used per treatment. Water and feed were offered ad libitum throughout the experimental period. The piglets were randomly assigned into one of five treatments. The feed compositions of dietary experiment are shown in Table 1. The basal control diet was formulated to meet the nutrient requirement of piglets according to the NRC (1998). Five treatments were: (1) -ve control (free antibiotic); (2)+ve control ( $0.03 \%$ antibiotic of chlortetracycline); (3) Com 1 ( $0.3 \%$ metabolite of TL1, RG11 and RI11 strains); (4) Com 2 ( $0.3 \%$ metabolite of TL1, RG14 and RS5 strains); (5) Com 3 ( $0.3 \%$ metabolite of RG11, RG14 and RI11 strains). The experiment was investigated for five consecutive weeks. The BW and feed intake were measured weekly. At the end of experimental period, three piglets with similar BW from each treatment were sacrificed for intestinal tissue and faeces samples.

\section{Diarrhoea observations and faeces sampling}

The diarrhoea score of each piglet was recorded on days 3, 5, 10, 12, 17 and 24. Diarrhoea was assessed visually from the scale 0 to 3 , based on the consistency of the faeces forms according to the following scores: $0=$ pellet faeces, $1=$ semi-pellet faeces, $2=$ soft faeces and $3=$ watery faeces. This observation was followed the method that described by Loh et al. (2002).

Faecal samples were collected directly from the rectum of the scarified piglets at slaughter and the $\mathrm{pH}$ was measured immediately after the collection. Faecal samples were then stored at $-20^{\circ} \mathrm{C}$ until further analyses for microfloral counts and SCFA.

Faecal LAB, ENT counts and SCFA contents

Ten percent $(\mathrm{w} / \mathrm{v})$ of faecal sample was diluted in sterile peptone water as prepared by $25.5 \mathrm{~g} / \mathrm{L}$ and homogenized to stand at room temperature for $1 \mathrm{~h}$. The samples were diluted $(10 \% \mathrm{v} / \mathrm{v})$ for further tenfold series with peptone water. The dilution was vortexed and spread using a sterile glass spreader. Enumerations of bacteria were performed on MRS agar for $\mathrm{LAB}$ and incubated in anaerobic jar at $30^{\circ} \mathrm{C}$ for $48 \mathrm{~h}$. ENT enumeration were performed on eosin methylene blue (EMB; Merck, Darmstadt, Germany) agar and incubated an anaerobic condition at $37^{\circ} \mathrm{C}$ for $24 \mathrm{~h}$. Number of colony forming units (CFU) are expressed as $\log _{10}$ CFU per g. Faecal SCFA contents were determined 
Table 1 Composition of piglet basal diet combination of TL1, RG11 and RI11; Com 2 is a combination of TL1, RG14 and RS5; Com 3 is a combination of RG11, RG14 and RI11

${ }^{1}$ The vitamin premix provided the following amounts per kilogram of diet: retinol

$5.8 \mathrm{mg}$; cholecalciferol $75 \mu \mathrm{g}$; $\alpha$-tocopherol $36 \mathrm{mg}$; thiamine $4.0 \mathrm{mg}$; riboflavin $6.0 \mathrm{mg}$; calpan $40 \mathrm{mg}$; niacin $38 \mathrm{mg}$; pyridoxine $4.2 \mathrm{mg}$; menadione, $4.5 \mathrm{mg}$; folic acid $1.5 \mathrm{mg}$; cyanocobalamin $42 \mu \mathrm{g}$ and biotin $0.1 \mathrm{mg}$

${ }^{2}$ The mineral premix provided the following amounts per kilogram of diet: manganese $100 \mathrm{mg}$; iron $80 \mathrm{mg}$; zinc $80 \mathrm{mg}$; copper $100 \mathrm{mg}$; cobalt $80 \mathrm{mg}$; iodine $70 \mathrm{mg}$ and selenium $50 \mathrm{mg}$; monocalcium phosphorus: phosphorus $21 \%$; calcium $17 \%$ and fluorine $0.21 \%$

\begin{tabular}{|c|c|c|c|c|c|}
\hline \multirow[t]{2}{*}{ Item } & \multicolumn{5}{|c|}{ Dietary of treatments } \\
\hline & -Ve control & +Ve control & Com 1 & Com 2 & Com 3 \\
\hline \multicolumn{6}{|l|}{ Ingredients, $\%$ as-fed } \\
\hline Corn & 38.50 & 38.50 & 38.50 & 38.50 & 38.50 \\
\hline Soybean & 30.00 & 30.00 & 30.00 & 30.00 & 30.00 \\
\hline Fine corn meal & 12.75 & 12.75 & 12.75 & 12.75 & 12.75 \\
\hline Wheat pollard & 5.15 & 5.12 & 4.85 & 4.85 & 4.85 \\
\hline Monocalcium phosphorus & 0.5 & 0.5 & 0.5 & 0.5 & 0.5 \\
\hline Salt & 0.5 & 0.5 & 0.5 & 0.5 & 0.50 \\
\hline Milk powder & 5.00 & 5.00 & 5.00 & 5.00 & 5.00 \\
\hline Lactose & 5.50 & 5.50 & 5.50 & 5.50 & 5.50 \\
\hline Calcium carbornate & 0.50 & 0.50 & 0.50 & 0.50 & 0.50 \\
\hline L-lysine & 0.15 & 0.15 & 0.15 & 0.15 & 0.15 \\
\hline DL-methionine & 0.12 & 0.12 & 0.12 & 0.12 & 0.12 \\
\hline L-tryptophan & 0.05 & 0.05 & 0.05 & 0.05 & 0.05 \\
\hline Vitamin premix ${ }^{1}$ & 0.28 & 0.28 & 0.28 & 0.28 & 0.28 \\
\hline Minerals premix ${ }^{2}$ & 0.50 & 0.50 & 0.50 & 0.50 & 0.50 \\
\hline Choline chloride $50 \%$ & 0.50 & 0.50 & 0.50 & 0.50 & 0.50 \\
\hline Chlotetracyline & - & 0.03 & - & - & - \\
\hline Metabolite & - & - & 0.3 & 0.3 & 0.3 \\
\hline Total & 100.00 & 100.00 & 100.00 & 100.00 & 100.00 \\
\hline \multicolumn{6}{|c|}{ Calculated analyses, DM basis } \\
\hline Crude protein, $\%$ & 21.08 & 21.09 & 21.12 & 21.10 & 21.08 \\
\hline $\mathrm{ME}, \mathrm{MJ} / \mathrm{kg}$ & 14.22 & 14.20 & 14.30 & 14.28 & 14.24 \\
\hline
\end{tabular}

using gas chromatography as described by Thanh et al. (2009).

Villus height and crypt depth

The samples from the middle of duodenum, jejunum and ileum of small intestine of each segment were sectioned 6$8 \mathrm{~cm}$, flushed and kept in neutral buffered formalin solution until further morphometric analysis. The samples were then cut into two parts from each segment for cross and length section of intestine surface. Each segment was fixed in $10 \%$ formalin. Intestinal samples were excised and dehydrated for $16 \mathrm{~h}$ in a tissue processing machine (Leica ASP 3000, Japan) and then embedded in paraffin wax (Leica EG 1160, Japan). Each section was cut $4 \mu \mathrm{m}$ thick (Leica RM 2155, Japan) and fixed on to the glass slides, heated at $57^{\circ} \mathrm{C}$ until samples were dried. The samples were stained with haematoxylin and eosin, mounted with coverslips. The villus height was measured as the distance between the crypt mouth and the tip of villi. The crypt depth was measured as the distance between the basement membrane and the mouth of crypt as using microscopes and read by PC Life Science Olympus software (Olympus Soft Imaging Solutions). This procedure was based on the method described by Bejo (1990).
Statistical analyses

Data were analysed using one-way analysis of variance. The effects of diet treatments on different animals and faecal parameters were tested using the General Linear Model procedure of SAS 1998 (SAS Inst., Inc., Cary, NC). Initial BW was used as a covariate in analyses of piglet performances. As for faecal consistency analyses, the pen was used as main effect of sampling day in the model. Duncan's multiple range test system was used to compare the significant difference of treatments at $P<0.05$. The data were presented as the mean \pm SEM.

\section{Results}

Growth performance and diarrhoea score

Initial BW was not significantly different $(P>0.05)$ among the treatment groups. However, the final BW for the - ve control was significantly lower $(P<0.05)$ than Com 2 and the + ve control (Table 2). No significant differences $(P>$ 0.05 ) were found between the + ve control group and metabolite treatment groups. The average daily gain 
Table 2 Growth performance and diarrhoea score of piglets fed with different dietary treatments

\begin{tabular}{|c|c|c|c|c|c|c|}
\hline \multirow[t]{2}{*}{ Item } & \multicolumn{5}{|c|}{ Dietary of treatments } & \multirow[t]{2}{*}{$P$ values } \\
\hline & -Ve Control & + Ve control & Com 1 & Com 2 & Com 3 & \\
\hline Initial BW, kg & $6.20 \pm 0.19$ & $6.64 \pm 0.18$ & $6.18 \pm 0.12$ & $6.21 \pm 0.09$ & $6.34 \pm 0.13$ & 0.16 \\
\hline Final BW, kg & $12.82 \pm 0.48^{\mathrm{b}}$ & $14.12 \pm 0.35^{\mathrm{a}}$ & $13.62 \pm 0.24^{\mathrm{ab}}$ & $14.11 \pm 0.32^{\mathrm{a}}$ & $13.59 \pm 0.33^{\mathrm{ab}}$ & 0.08 \\
\hline $\mathrm{ADG}, \mathrm{g}$ & $186.7 \pm 9.8^{\mathrm{b}}$ & $213.0 \pm 7.9^{\mathrm{a}}$ & $213.4 \pm 5.4^{\mathrm{a}}$ & $224.9 \pm 8.1^{\mathrm{a}}$ & $207.3 \pm 7.9^{\mathrm{ab}}$ & 0.02 \\
\hline ADFI, $g$ & $378.3 \pm 17.1$ & $398.1 \pm 18.2$ & $389.0 \pm 20.6$ & $399.7 \pm 14.7$ & $380.4 \pm 16.6$ & 0.86 \\
\hline FCR & $2.17 \pm 0.16^{\mathrm{a}}$ & $1.89 \pm 0.07^{\mathrm{b}}$ & $1.82 \pm 0.06^{\mathrm{b}}$ & $1.80 \pm 0.07^{\mathrm{b}}$ & $1.87 \pm 0.07^{\mathrm{b}}$ & 0.05 \\
\hline \multicolumn{7}{|l|}{ Diarrhoea score } \\
\hline Day 0-24 & $0.56 \pm 0.15^{\mathrm{a}}$ & $0.24 \pm 0.07^{\mathrm{bc}}$ & $0.51 \pm 0.11^{\mathrm{a}}$ & $0.14 \pm 0.05^{\mathrm{c}}$ & $0.31 \pm 0.10^{\mathrm{b}}$ & 0.09 \\
\hline
\end{tabular}

Means \pm SEM within the same row with different superscripts are significantly different at $P<0.05$

The Com 1 metabolite is a combination of TL1, RG11 and RI11; Com 2 is a combination of TL1, RG14 and RS5; Com 3 is a combination of RG11, RG14 and RI11

$A D F I$ average daily feed intake

(ADG) for the - ve control group was significantly poorer $(P<0.05)$ than other treatments except for the Com 3. The average daily feed intake was not significantly different $(P>0.05)$ among the treatments during the 5 weeks of the experiment trial. The FCR was the highest $(P<0.05)$ in the -ve control group and no significant difference $(P>0.05)$ was found between the + ve control and metabolite treatment groups.

The piglets fed with Com 2 and Com 3 treatments demonstrated significant lower $(P<0.05)$ diarrhoea scores compared to the -ve control and Com 1 groups. However, there were no significant differences $(P>0.05)$ between Com 2, Com 3 and the + ve control group. No diarrhoea incidence of piglets was observed after 24 days of posweaning (Fig. 1).

Faecal $\mathrm{pH}$, microfloral population and SCFA

The Com 2 group had significantly lower $(P<0.05)$ faecal $\mathrm{pH}$ than the - ve control group. No significant differences

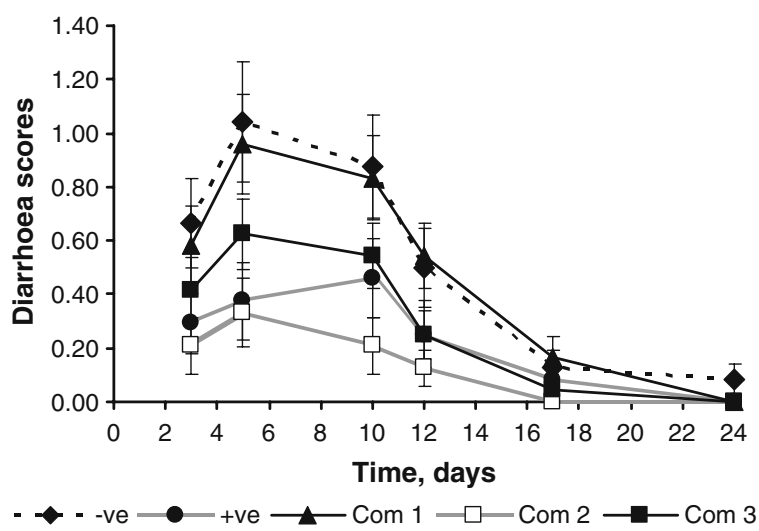

Fig. 1 Diarrhoea scores in piglets fed with different dietary treatments
$(P>0.05)$ were found between metabolite combination groups (Table 3). Faecal LAB counts of metabolite treatment groups were significantly higher $(P<0.05)$ than those without metabolite combinations (Table 3). No significant differences $(P>0.05)$ were found for LAB counts in Com 1, Com 2 and Com 3 metabolite treatment groups. However, the Com 2 treatment showed a significant lower $(P<0.05)$ faecal ENT counts when compared to the -ve control, Com 1 and Com 3 treatment groups.

The main composition of faecal SCFA was acetic acid and there was no significant difference $(P>0.05)$ among the treatment groups in the current experiment (Table 3). The concentration of propionic acid in Com 2 group was significantly higher $(P<0.05)$ than those presented in - ve and + ve control groups. In addition, the propionic acid in Com 1 group was also significantly higher $(P<0.05)$ than those obtained in the - ve control group. Butyric acid in Com 2 treatment was the highest $(P<0.05)$ among all the treatment groups. Isovaleric acid in Com 1 treatment was significantly higher $(P>0.05)$ as compared to control group. There was no significant difference $(P>0.05)$ for isobutyric and valeric acids in the piglet faeces among treatment groups. Total faecal SCFA in the Com 2 treatment was significantly higher $(P<0.05)$ than those of the - ve control group but did not present any significant differences $(P>0.05)$ between the antibiotic group and metabolite treatment groups.

Villus height and crypt depth

The duodenal villus height was significantly higher $(P<$ 0.05) in the + ve control and Com 2 treatment groups compared to the - ve control group. However, no significant difference $(P>0.05)$ between treatment groups was observed in the jejunum and ileum villus height and for the intestinal crypt depth in the intestine of piglets (Table 4). 
Table 3 Faecal $\mathrm{pH}$, LAB, ENT population and SCFA concentration in piglets fed with different dietary treatments

Means \pm SEM within the same row with different superscripts are significantly different at $P<0.05$

The Com 1 metabolite is a combination of TL1, RG11 and RI11; Com 2 is a combination of TL1, RG14 and RS5; Com 3 is a combination of RG11, RG14 and RI11

Lactic acid was not included in total SCFA

\begin{tabular}{lllllll}
\hline Item & \multicolumn{2}{l}{ Dietary of treatments } & & \multirow{2}{*}{$P$ values } \\
\cline { 2 - 5 } & - Ve control & + Ve control & Com 1 & Com 2 & Com 3 & \\
\hline Faecal pH & $6.43 \pm 0.11^{\mathrm{a}}$ & $6.36 \pm 0.09^{\mathrm{ab}}$ & $6.24 \pm 0.11^{\mathrm{ab}}$ & $6.06 \pm 0.08^{\mathrm{b}}$ & $6.19 \pm 0.10^{\mathrm{ab}}$ & 0.12 \\
Microfloral counts, $\log _{10} \mathrm{CFU} / \mathrm{g}$ & & & & \\
LAB & $6.62 \pm 0.08^{\mathrm{b}}$ & $6.58 \pm 0.06^{\mathrm{b}}$ & $7.19 \pm 0.19^{\mathrm{a}}$ & $7.43 \pm 0.16^{\mathrm{a}}$ & $7.34 \pm 0.04^{\mathrm{a}}$ & $<0.001$ \\
ENT & $6.40 \pm 0.19^{\mathrm{a}}$ & $5.95 \pm 0.15^{\mathrm{ab}}$ & $6.40 \pm 0.24^{\mathrm{a}}$ & $5.75 \pm 0.07^{\mathrm{b}}$ & $6.41 \pm 0.13^{\mathrm{a}}$ & 0.02 \\
SCFA, mM/L & & & & & & \\
Acetic & $27.0 \pm 0.66$ & $28.5 \pm 0.79$ & $28.5 \pm 2.22$ & $29.3 \pm 2.35$ & $26.5 \pm 2.19$ & 0.79 \\
Propionic & $10.5 \pm 1.11^{\mathrm{c}}$ & $12.0 \pm 0.92^{\mathrm{bc}}$ & $13.8 \pm 1.08^{\mathrm{ab}}$ & $15.8 \pm 1.13^{\mathrm{a}}$ & $13.0 \pm 0.53^{\mathrm{abc}}$ & 0.01 \\
Isobutyric & $0.3 \pm 0.16$ & $0.4 \pm 0.03$ & $0.2 \pm 0.07$ & $0.3 \pm 0.08$ & $0.5 \pm 0.02$ & 0.24 \\
Butyric & $3.5 \pm 0.85^{\mathrm{b}}$ & $3.2 \pm 0.37^{\mathrm{b}}$ & $4.3 \pm 0.81^{\mathrm{b}}$ & $6.3 \pm 0.49^{\mathrm{a}}$ & $4.2 \pm 0.50^{\mathrm{b}}$ & 0.02 \\
Isovaleric & $0.3 \pm 0.007^{\mathrm{b}}$ & $0.3 \pm 0.03^{\mathrm{b}}$ & $0.4 \pm 0.05^{\mathrm{a}}$ & $0.4 \pm 0.04^{\mathrm{ab}}$ & $0.3 \pm 0.02^{\mathrm{ab}}$ & 0.08 \\
Valeric & $0.3 \pm 0.06$ & $0.4 \pm 0.16$ & $0.3 \pm 0.05$ & $0.4 \pm 0.02$ & $0.4 \pm 0.02$ & 0.81 \\
Total SCFA & $42.0 \pm 2.63^{\mathrm{b}}$ & $44.8 \pm 1.08^{\mathrm{ab}}$ & $47.6 \pm 3.08^{\mathrm{ab}}$ & $52.5 \pm 3.36^{\mathrm{a}}$ & $44.9 \pm 1.69^{\mathrm{ab}}$ & 0.07 \\
\hline
\end{tabular}

\section{Discussion}

In this experiment, metabolite combinations produced by L. plantarum strains improved BW, ADG and FCR in postweaning piglets compared to those piglets fed free antibiotic in diet (-ve control). However, there were no significant differences for growth performance between the metabolite treatment and+ve control groups. Better performances in animals fed with metabolite combinations could be due to the organic acids, bacteriocins, ethanol, hydrogen peroxide and vitamins present in the metabolites (Cintas et al. 2001; Foo et al. 2005; Biagi et al. 2006; Desouky and Ibrahim 2009). These results are in agreement with other studies that reported that metabolites produced by $L$. plantarum improved growth performance in postweaning rats (Foo et al. 2003) and broiler chickens (Thanh et al. 2009). Many previous studies have reported the positive effects of antimicrobial compounds produced by Lactobacillus spp. on growth performance in pigs (Hale and Newton 1979; Toit et al. 1998; Canibe et al. 2008). Current study showed that Com 2 (TL1, RG14 and RS5 strains) demonstrated a better growth performance than other treat- ments, indicating the Com 2 metabolites are a better choice compared to other combinations of metabolites.

The faecal $\mathrm{pH}$ and intestinal microflora population have been related to the diarrhoea incidence of postweaning piglets, especially the ENT population in the faeces (Loh et al. 2002). There are opportunities for ENT to multiply after weaning period in piglets when suffering from many stressors. The most common ENT family are Escherichia coli, Salmonella and Clostridium which frequently provoke diarrhoea incidence in young piglets. The reduction of faecal ENT population in the piglets fed with metabolites may be due to the ability of the metabolite to inhibit the growth of various Gram-negative bacteria. On the other hand, Taras et al. (2006) reported that SCFA could prevent the incidence of diarrhoea in piglets, which are the main substances present in metabolites used in this study. The inhibitory activity of ENT prevented the severity of diarrhoea incidence in postweaning piglets (Melin et al. 2004). The Com 2 metabolite combinations in our study increased the faecal LAB and reduced shedding of intestinal pathogens ENT. Similar results reported by Van Winsen et al. (2001) showed that there was a reduction in
Table 4 Villus height and crypt depth in small intestine of piglets fed with different dietary treatments

Means \pm SEM within the same row with different superscripts are significantly different at $P<0.05$

The Com 1 metabolite is a combination of TL1, RG11 and RI11; Com 2 is a combination of TL1, RG14 and RS5; Com 3 is a combination of RG11, RG14 and RI11

\begin{tabular}{lllllll}
\hline Item & \multicolumn{2}{l}{ Dietary of treatments } & & P values \\
\cline { 2 - 5 } & \multicolumn{1}{c}{-Ve control } & + Ve control & Com 1 & Com 2 & Com 3 & \\
\hline Villus height, $\mu \mathrm{m}$ & & & & & \\
Duodenum & $403.2 \pm 23.7^{\mathrm{b}}$ & $498.7 \pm 14.2^{\mathrm{a}}$ & $441.9 \pm 28.3^{\mathrm{ab}}$ & $490.6 \pm 18.3^{\mathrm{a}}$ & $473.3 \pm 35.3^{\mathrm{ab}}$ & 0.07 \\
Jejunum & $382.5 \pm 11.0$ & $402.5 \pm 28.3$ & $408.2 \pm 15.6$ & $454.9 \pm 21.5$ & $439.5 \pm 30.8$ & 0.19 \\
Ileum & $345.1 \pm 13.7$ & $406.7 \pm 29.1$ & $384.1 \pm 12.9$ & $411.9 \pm 17.4$ & $410.6 \pm 26.1$ & 0.15 \\
Crypt depth, & $\mu \mathrm{m}$ & & & & & \\
Duodenum & $225.9 \pm 10.5$ & $203.2 \pm 23.8$ & $203.9 \pm 14.0$ & $220.8 \pm 14.5$ & $198.8 \pm 14.8$ & 0.69 \\
Jejunum & $202.3 \pm 10.7$ & $187.1 \pm 16.0$ & $189.0 \pm 14.3$ & $193.6 \pm 10.6$ & $179.3 \pm 11.8$ & 0.78 \\
Ileum & $180.9 \pm 5.7$ & $189.6 \pm 14.3$ & $167.9 \pm 7.5$ & $168.2 \pm 7.5$ & $157.5 \pm 14.9$ & 0.27 \\
\hline
\end{tabular}


faecal ENT when fed fermented feed containing $L$. plantarum in diet of pigs. Feeding of spray-dried metabolite from $L$. plantarum also decreased ENT in the faeces of postweaning rats (Loh et al. 2009). The effects of metabolite produced by $L$. plantarum could reduce the faecal $\mathrm{pH}$ due to the production of organic acids such as lactic, acetic, propionic and butyric acids. The low faecal $\mathrm{pH}$ level was not an optimum environmental condition for ENT development. However, it is a good environment for LAB development (Holzapfel et al. 1998). The production of lactic acid and SCFA respond to the $\mathrm{pH}$ reduction of the intestinal mucosa (Taras et al. 2006). Moreover, LAB in the metabolite treatments was able to compete with ENT pathogens for the surface and nutrients in the gastrointestinal tract and increased the available energy in the host (Abu-Tarboush et al. 1996; Canibe et al. 2008; Niba et al. 2009). According to Foo et al. (2005), metabolites produced by existing bacteria present in the gut were able to reduce $\mathrm{pH}$ further by fermentation process. Longland (1991) reported that the metabolites in the animal diet could allow suitable conditions for pepsin activity, which is necessary for protein degradation in stomach (Lawlor et al. 2002). Many studies have shown the beneficial impact of LAB and their metabolite by: (1) prevention against pathogens and infectious diseases in the gut; (2) enhance immunity response by remove toxics and antitumor development; (3) stimulate activity of bile salt hydrolase to transfer cholesterol for therapeutics and absorption; (4) provide nutrition substances (Fuller 1989; Holzapfel et al. 1998; Heyman 2000).

The SCFA that comprises acetic, propionic, isobutyric, butyric, isovaleric and valeric acid are absorbed mostly in large intestine and provide energy to the host (Franklin et al. 2002), particularly butyric acid can contribute significantly to the health of the colon mucosa (Niba et al. 2009). In this study, the piglets fed with Com 2 metabolite combination increased the total faecal SCFA, propionic and butyric acids in piglets. Thanh et al. (2009) demonstrated that chicken fed metabolite combinations increased SCFA concentrations in the faeces. Furthermore, the stability of the colon mucosa is dependent on SCFA concentration produced by the colonic microfloral (Franklin et al. 2002). The products of polysaccharide metabolism SCFA are passively absorbed by the enterocytes and stimulated the growth of the hindgut mucosa (Mathew et al. 1996; Biagi et al. 2006). McHan and Shottls (1993) estimated $40-50 \%$ of energy requirement was provided by SCFA colonic microflora.

Postweaning piglets commonly suffered morphology atrophy and crypt hyperplasia that could limit the absorption of voluntary feed intake and weight gain after weaning (Loh et al. 2002; Hedemann et al. 2003). Measurement of intestinal villus height and crypt depth was determined for the surface area of intestine undertaken for nutrient absorption. The present results showed that metabolite combinations did not affect the crypt depth of piglets after receiving different treatments for 5 weeks. However, the duodenal villus height was higher in Com 2 treatment compared to the -ve control group, indicating the feeding of metabolite would improve the height of villus, particularly at the duodenum. The development in villus height at different segments of small intestine might be attributed to the role of the intestine epithelium as a natural barrier (Paul et al. 2007).

In conclusion, the interactions between faecal $\mathrm{pH}$, SCFA and microfloral population were important to provide the balance of metabolism and the health of gut. The positive development of LAB population, SCFA compositions, and reduction of $\mathrm{pH}$ and ENT in the gastrointestinal tract of animals were obtained in this study, implying the metabolite combinations produced by L. plantarum strains are potential alternatives to antibiotics that could be used as growth promoter in animals. The combination of metabolites produced by TL1, RG14 and RS5 strains demonstrated the best effect for growth performance in piglets.

Open Access This article is distributed under the terms of the Creative Commons Attribution Noncommercial License which permits any noncommercial use, distribution, and reproduction in any medium, provided the original author(s) and source are credited.

\section{References}

Abu-Tarboush, H.M., Al-Saiady, M.Y. and Keir El-Din, A.H., 1996. Evaluation of diet containing Lactobacilli on performance, fecal Coliform, and Lactobacilli of young dairy calves. Animal Feed Science and Technology 57(1-2), 39-49.

Bejo, M.H., 1990. Gastrointestinal response to copper excess: studies on copper (and zinc) loader rats. $\mathrm{PhD}$ Thesis, University of Liverpool, UK.

Biagi, G., Piva, A., Moschini, M., Vezzali, E. and Roth, F.X., 2006. Effect of gluconic acid on piglet growth performance, intestinal microflora, and intestinal wall morphology. Journal of Animal Science 84, 370-378.

Canibe, N., Miettinen, H. and Jensen, B.B., 2008. Effect of adding Lactobacillus plantarum or a formic acid containing-product to fermented liquid feed on gastrointestinal ecology and growth performance of piglets. Livestock Production Science 114(2-3), 251-262.

Cintas, L.M., Casaus, M.P., Herranz, C., Nes, I.F. and Hernandez, P.E., 2001. Review: bacteriocins of lactic acid bacteria. Food Science and Technology International 7(4), 281-305.

Desouky, S.G. and Ibrahim, S.M., 2009. Effect of antimicrobial metabolites produced by lactic acid bacteria (Lab) on quality aspects of frozen tilapia (Oreochromis niloticus) fillets. World Journal of Fish and Marine Sciences 1(1), 40-45.

Foo, H.L., Loh, T.C., Law, F.L., Lim, Y.Z., Kufli, C.N. and Rusul, G., 2003. Effects of feeding Lactobacillus plantarum I-UL4 isolated from Malaysian Tempeh on growth performance, faecal flora and lactic acid bacteria and plasma cholesterol concentrations in postweaning rats. Food Science and Biotechnology 4, 403-408. 
Foo, H.L., Lim, Y.S., Loh, T.C., Saleh, N.M., Raha, A.R. and Rusul, G., 2005. Characterization of bacteriocin produced by Lactobacillus plantarum I-UL4 isolated from Malaysian fermented tapioca, Tapai Ubi. Proceeding of 4th NIZO Dairy Conference, Papendal, Netherland, p. 33.

Franklin, M.A., Mathew, A.G., Vickers, J.R. and Clift, R.A., 2002. Characterization of microbial populations and volatile fatty acid concentrations in the jejunum, ileum, and cecum of pigs weaned at 17 vs 24 days of age. Journal of Animal Science 80, 29042910.

Fuller, R., 1989. Probiotics in man and animals. Journal of Applied Bacteriology 66, 365-378.

Hale, O.M. and Newton, G.L., 1979. Effecs of a nonviable Lactobacillus species fermentation product on performance of pigs. Journal of Animal Science 48(4), 770-775.

Hedemann, M.S., Højsgaard, S. and Jensen, B.B., 2003. Small intestinal morphology and activity of intestinal peptidase in piglets around weaning. Journal of Animal Physiology and Animal Nutrition 87, 32-41.

Heyman, M., 2000. Effect of lactic acid bacteria on diarrhoeal diseases. Journal of the American College of Nutrition 19(2), 137-146.

Holzapfel, W.H., Haberer, P., Snel, J., Schillinger, U. and Huis in't Veld, J.H.J., 1998. Overview of gut flora and probiotics. International Journal of Food Microbiology 41(2), 85-101.

Jensen, B.B., 1998. The impact of feed additive on the microbial ecology of the gut in the young pigs. Journal of Animal Feed and Science Technology 89, 175-188.

Jones, F.T., Langlosis, B.E., Gromwell, G.L. and Hays, V.W., 1984. Effect of chlortetracycline on the spread of R-100 plasmidcontaining Escherichia coli bel15R from experimentally infected pigs to uninfected pigs and chicks. Journal of Animal Science 58 (3), 519-526.

Lawlor, P.G., Lynch, P.B., Gardiner, G.E., Caffrey, P.J. and O'Doherty, J.V., 2002. Effect of liquid feeding weaned pigs on growth performance to harvest. Journal of Animal Science 80(7), 17251735.

Longland, A.C., 1991. Digestive enzyme activities in pigs and poultry. In vitro digestion for pigs and poultry. Page3. CAB International, Wallingford, Oxon, UK.

Loh, T.C., Choo, P.Y. and Cheong, Y.H., 2002. Effects of organic acid and natural herbs on performance and incidence of diarrhoea in postweaning pigs. Malaysian Journal of Animal Science 7(2), 2530.

Loh, T.C., Chong, S.W., Foo, H.L. and Law, F.L., 2009. Effects on growth performance, faecal microflora and plasma cholesterol after supplementation of spray-dried metabolite to postweaning rats. Czech Journal Animal Science 54(1), 10-16.
Makkink, C.A., Berntsen, P.J., Op den Kamp, B.M., Kemp, B. and Verstegen, M.W., 1994. Gastric protein breakdown and pancreatic enzyme activities in response to two different dietary protein sources in newly weaned pigs. Journal of Animal Science 72, 2843-2850.

Mathew, A.G., Franklin, M.A., Upchurch, W.G. and Chattin, S.E., 1996. Effects of weaning on ileal short chain fatty acid concentration in pigs. Nutrition Research 16 (10), 1689-1698.

McHan, F. and Shottls, F.B., 1993. Effects of short chain fatty acids on the growth of $S$. typhimurium in an vitro system. Avian Diseases 37(2), 396-398.

Melin, L., Mattson, S., Katouli, M. and Wallgren, P., 2004. Development of post-weaning diarrhoea in piglets. Relation to presence of Escherichia coli strains and rotavirus. Journal of Veterinary Medicine 51(1), 12-22.

National Research Council (NRC), 1998. Nutrient Requirements of Swine. $9^{\text {th }}$ revised edition, National Academies Press, Washington, DC.

Niba, A.T., Beal, J.D., Kudi, A.C. and Brooks, P.H., 2009. Bacterial fermentation in the gastrointestinal tract of non-ruminant: influence of fermented feeds and fermentable carbohydrates. Tropical Animal Health and Production 41, 1393-1407.

Paul, S. K., Halder, G., Mondai, M.K. and Samanta, G., 2007. Effect of organic acid salt on the performance and gut health of broiler chicken. Journal of Poultry Science 44, 389-395.

Roth, F.X. and Kirchgessner, M., 1998. Organic acids as feed additive for young pigs: nutritional and gastrointestinal effects. Journal of Animal and Feed Science 7, 25-33.

Taras, D., Vahjen, W., Macha, M. and Simon, O., 2006. Performance, diarrhea incidence, and occurrence of Escherichia coli virulence genes during long-term administration of a probiotic Enterococcus faecium strain to sows and piglets. Journal of Animal Science 84(3), 608-617.

Thanh, N.T., Loh, T.C., Foo, H.L., Hair-bejo, M. and Azhar, B.K., 2009. Effects of feeding metabolite combinations produced by Lactobacillus plantarum on growth performance, faecal microbial population, small intestine villus height and faecal volatile fatty acids in broilers. British Poultry Science 50(3), 298-306.

Toit, M., Franz, C., Dicks, L., Schillinger, U., Haberer, P., Warlies, B., Ahrens, F. and Holzapfel, W., 1998. Characterization and selection of probiotic Lactobacilli for a preliminary minipig feeding trial and their effect on serum cholesterol levels, faeces $\mathrm{pH}$ and faeces moisture content. International Journal of Food Microbiology 40, 93 - 104.

Van Winsen, R.L., Urlings, B.A.P., Lipman, L.J.A., Snijders, J.M.A., Keuzenkamp, D., Verheijden, J.H.M. and Van Knapen, F., 2001. Effect of fermented feed on the microbial population of the gastrointestinal tracts of pigs. Applied and Environmental Microbiology 67 (7), 3071-3076. 